\title{
Çocuk Hekimlerinin Geleneksel ve Tamamlayıcı Tıp Tedavisi Uygulamaları ile İl- gili Bilgi ve Tutumlarının Değerlendirilmesi
}

\section{Evaluation of Knowledge and Attitudes of Pediatricians on Traditional and Complementary Medicine Treatment Practices}

\author{
Sema ATEŞ ${ }^{1 *}$, Ali GÜNGÖR² ${ }^{[0}$
}

Atıf Yapmak İçin: Ateş S, Güngör A. Çocuk hekimlerinin geleneksel ve tamamlayıc1 tıp tedavisi uygulamaları ile ilgili bilgi ve tutumlarının değerlendirilmesi. Van Sag Bil Derg 2021, 14, (1): 7 18.

https://doi.org/10.52976/van saglik.752863.

Geliş Zamanı: 15/06/2020

Kabul Zamanı: 01/11/2020

Basılama Zamanı: 30/04/2021
1 Dr. Sami Ulus Kadın Doğum Çocuk Sağlığı ve Hastalıkları Eğitim Araştırma Hastanesi, Çocuk Kardiyoloji A.D. Ankara, TÜRKIYY.

2 Dr. Sami Ulus Kadın Doğum Çocuk Sağlığı ve Hastalıkları Eğitim Araştırma Hastanesi, Çocuk Acil A.D. Ankara, TÜRKIYE.

* Sorumlu yazar: Sema ATEŞ; E-mail: drcici86@hotmail.com.

\section{ÖZET}

Amaç: Son yıllarda dünyada ve ülkemizde "Geleneksel ve Tamamlayıcı Tıp" (GTT) uygulamalarında ve ürünlerinin kullanımında artış izlenmektedir. Hekimler GTT uygulamalarının gerekliliği, yararları veya olası komplikasyonları konusunda tam bir görüş birliğine sahip değildir. Bu çalışmada çocuk hekimlerinin GTT uygulamaları konusundaki bilgi ve görüşlerini değerlendirmek amaçlanmıştır.

Materyal ve Metot: Bu çalışmada Ankara Çocuk Sağlığı ve Hastalıkları Hematoloji Onkoloji Eğitim ve Araştırma Hastanesi'nde çalışmakta olan çocuk sağlığı ve hastalıkları ile yan dallarında görev yapan hekimlerin GTT uygulamaları konusundaki bilgi ve görüşlerini değerlendirmek amaçlanmıştır. Çalışmaya Haziran 2019- Eylül 2019 tarihlerinde görev yapan 216 çocuk hekimi dahil edilmiştir. Araştırma kesitsel tipte olup verilerin toplanmasında anket kullanılmıştır.

Bulgular: 175 kadın 41 erkek çocuk hekiminden oluşan katılımcılar arasında, GTT konusunda en fazla bilinen yöntemler olarak probiyotikler \%29,2, masaj \%13,4, balneoloji \%11,5, akupunktur \%8,7 ve bitkisel tedaviler \%8,7 öne çıkmaktadır. Katılımcıların en çok kullandığı yöntemlerin masaj (\%21,8), bitkisel tedaviler $(\% 9,7)$ ve akupunktur $(\% 8,8)$ olduğu görülmüştür. Çocuk hekimlerinin \%90,7'si daha önce GTT konusunda herhangi bir eğitim almadıklarını, \%69'u ise bu konuda tıp fakültesi eğitimi sürecinde ders konulmasını istediklerini belirtmişlerdir.

Sonuç: Çocuk hekimlerinin GTT yöntemleri konusunda bilgi ve deneyimlerinin yetersiz olduğu, bu yöntemlerin yan etkilerinin çocuklarda daha sık olabileceği ve tıp fakültesi veya uzmanlık döneminde konu ile ilgili eğitim almak istedikleri tespit edilmiştir. Çocuk hekimlerinin GTT yöntemleri konusunda bilgi ve deneyimlerinin yetersiz olduğu ve tıp fakültesi veya uzmanlık döneminde konu ile ilgili eğitim almak istedikleri tespit edilmiştir.

Anahtar Kelimeler: Anket, Farkındalık, Prenatal tanı.

\section{ABSTRACT}

Aim: In recent years, there has been an increase in "Traditional and Complementary Medicine" (GTT) practices and use of products in the world and in our country. Physicians do not have a full consensus on the necessity, benefits or possible complications of GTT applications. In this study, it is aimed to evaluate the knowledge and opinions of pediatricians about GTT applications.

Materials and Methods: In this study, it is aimed to evaluate the knowledge and opinions of the doctors working in Ankara Child Health and Diseases Hematology Oncology Training and Research Hospital about GTT practices. 216 pediatricians working from June 2019 to September 2019 were included in the study. The research is cross-sectional and the questionnaire was used to collect the data.

Results: Among the participants consisting of 175 female and 41 male pediatricians, probiotics standout as $29.2 \%$, massage $13.4 \%$, balneology $11.5 \%$, acupuncture $8.7 \%$ and herbal treatments $8.7 \%$ as known methods. The most commonly used methods were massage (21.8\%), herbal treatments $(9.7 \%)$ and acupuncture $(8.8 \%) .90 .7 \%$ of the pediatricians stated that they have not received any training on GTT before, and $69 \%$ stated that they want to have a course in the medical education process in this regard.

Conclusions: It has been determined that pediatricians have insufficient knowledge and experience on GTT methods and they want to receive education about the subject in the medical schoolor in the specialty period.

Keywords: Questionaire, Awareness, Prenatal diagnosis 


\section{GİRIŞ̧}

Dünya Sağlık Örgütü'ne (DSÖ) göre Geleneksel ve Tamamlayıcı Tıp (GTT) yöntemleri; fiziksel ve ruhsal hastalıklardan korunma, bunlara tanı koyma, iyileştirme veya tedavi etmenin yanında sağlığın iyi sürdürülmesinde de kullanılan, farklı kültürlere özgü teori, inanç ve tecrübelere dayalı -izahı yapılabilen veya yapılamayan- bilgi, beceri ve uygulamalar bütünüdür (World Health Org., 2000; Tokaç, 2013).

Modern tıbbın bu tür yöntemleri bilimsel açıklamalar ile temellendirilmediği gerekçesi ile dışlaması, ancak pratikte popülerliğinin giderek artışı sonucunda GTT uygulamalarını bilimsel bir temele oturtmak, güvenilirliği ve etkinliği kanıtlanmış uygulamaların modern tedavilerde kullanımını sağlamak amacı ile Amerika Birleşik Devletleri (ABD)'nde 1998' de Ulusal Tamamlayıcı ve Alternatif Tip Merkezi (The National Center for Complementary and Alternative Medicine-NCCAM) kurulmuştur (Pearson ve ark., 2007). Ülkemizde ise Sağlik Bakanlığ tarafından hazırlanan Geleneksel ve Tamamlayıcı Tıp Uygulamaları Yönetmeliği 27 Ekim 2014 tarihinde 29158 sayı ile Resmî Gazete ‘de yayımlanarak yürürlüğüne girmiştir (Resmi Gazete, 2014). Bu uygulamaların denetiminin, Sağlık Bakanlığı kapsamına alınmasıyla da ülkemizde pek çok sağlık merkezinde de çeşitli GTT yöntemleri hastalara uygulanmaya başlanmıştır. Dünya üzerinde GTT; bitkisel tedaviler, aromaterapi, akupunktur, kupa tedavisi, biyofeedbeck, hipnoz, meditasyonyoga, reiki, hirudoterapi, biyoenerji, ozon tedavisi, ayurveda, balneoloji, kayropraktik, TaiChi/QiGong gibi çeşitli yöntemle uygulanmaktadır. Akupunktur, vücut üzerinde belirli noktalara ince iğnelerin bat1rılması ile uygulanan Geleneksel Çin tıbbının bir türü olan tedavi yöntemidir (Herringve Roberts 2002). Aromaterapi, bitkisel ürünler ve yağlarla yapılan bir geleneksel tedavi yöntemidir (Resmî Gazete 2014). Hirudoterapi, steril sülüklerin vücuttan kan emerken aynı zamanda dokuya biyoaktif madde içeren bir salgı enjekte etmesiyle gerçekleşen tedavi yöntemidir (Ayhan ve Mollahaliloğlu, 2018).
Kupa uygulaması (hacamat), vücudun belli bölgelerine kesik atılıp kupa vurularak kan dolaşımını hızlandırmak ve kılcal damarlardaki kirli kanın dışarı atılması için yapılan tedavi yöntemidir (Benli, 2017). Ozon tedavisi, birçok hastalık sonucu bozulmuş olan fonksiyonların yeniden canlandırılması için vücut boşluklarına ya da dolaşım sistemine ozon/oksijen karışımının uygulanması olarak tanımlanmaktadır (Kutlubay ve ark., 2010). Ayurveda; özellikle Hindistan'da binlerce yılı aşkın süredir vücut, zihin ve ruhu dengeleme amaciyla kullanılan bir yöntemdir. Balneoloji; yer altı, toprak, su ve iklim kaynaklı doğal iyileştirici faktörlerle yapılan banyo, içme ve inhalasyon kürleri şeklinde uygulanan bir yöntemdir. Kayropraktik; sinir sistemini düzenlemek amacryla omurga, kemik ve kaslara müdahale etmeyi kapsayan el uygulamalarını içeren bir GTT yöntemidir. TaiChi/QiGong; bedende enerji dengesini artırmak için belirli fiziksel duruşlar ile beraber nefes tekniklerinin kullanıldı ğ1 yöntemdir. Osteopati; kasiskelet sisteminin etkinliği üzerinde duran elle uygulanan bir manuel terapi yöntemidir.

Günümüzde, toplumdaki birçok birey gerek tedavi gerek koruyucu amaçlı gerekse kültürel olarak GTT yöntemlerine gittikçe artan oranlarda başvurmaktadır. Son yapılan çalışmalar, çocuklarda GTT kullanıminın oldukça yaygın olduğunu, kullanılma sıklığının \%18.4-95.0 arasında değiştiğini göstermektedir (Bülbül ve ark., 2009; Sanders ve ark., 2003). Amerikan Pediatri Akademisi verilerine göre de GTT kullanımı sıklığı sağlıklı çocuklarda \%20-40, hastalığ1 olan çocuklarda ise \%50 olup azımsanamayacak boyuttadır (Kemper ve ark., 2008). Toplumda kullanımı yaygın olmasına karşın, toplumun yöntem çeşitliliği ve bu uygulamaların zarar ve yan etkileri konusundaki bilgisinin yeterli olmadığ 1 da benzer çalışmalarda vurgulanmıştır (Orhan ve ark., 2003; Sanders ve ark., 2003).

Günümüzde GTT yöntemlerinin erişkinlerde ve çocuklarda kullanımı birçok ülkede her geçen gün artmaktadır. İnsanların GTT hizmetlerinden yararlanmalarının nedenleri arasında kültürleriyle uyumlu olması, maliyetinin daha az olması, daha basit bir 
şekilde ulaşılması, girişimsel işlemlerin olmaması ya da daha az olması ve kronik, psikiyatrik ve terminal dönem hastalıklara umut olarak görülmesi sayılabilmektedir. Bu nedenle hekimler günlük pratiklerinde bu yöntemleri kullanan hastalarla sıkça karşılaşacaktır. Hekimlerin hastalarını bu konuda doğru yönlendirmeleri gerekmektedir. Ülkemizde çocuk hekimlerinin GTT uygulamaları hakkındaki bilgi ve görüşlerine yönelik araştırmalar sınırlıdır (Yıldırım ve ark., 2010; Akan ve ark., 2012). Çalışmamizda çocuk hekimlerinin GTT uygulamaları hakkındaki bilgi düzeylerini, tutum ve davranışlarını değerlendirmeyi amaçladık.

\section{MATERYAL ve METOT}

Çalışmamıza Haziran 2019- Eylül 2019 tarihleri arasında Ankara Çocuk Sağlığı ve Hastalıkları Hematoloji Onkoloji Eğitim ve Araştırma Hastanesi'nde çocuk sağlığı ve hastalıkları ile yan dallarında görev yapan toplam 216 hekim dahil edilmiştir. Çalışma için Ankara Çocuk Sağlığı ve Hastalıkları Hematoloji Onkoloji Eğitim ve Araştırma Hastanesi klinik araştırmalar etik kurulundan 2019-142 karar numarası ile etik kurul onayı alınmıştır. Araştırma kesitsel tipte olup verilerin toplanmasında yüz yüze yapılan 20 soruluk anket çalışması kullanılmıştır. Literatürden faydalanılarak hazırlanan ankette katılımcıların yaşı, cinsiyeti, unvan ve çalışma süresi gibi tanımlayıcı sorular ve GTT uygulamaları ile ilgili bilgi tutum ve davranışlarının ayrıntılı olarak değerlendirildiği sorular bulunmaktayd1.

İstatistiksel Analiz: Verilerin istatistiksel analizleri Statistical Package for the Social Sciences (SPSS) version 25.0 istatistik paket programında yapılmıştır. Tanımlayıcı istatistiklerde yüzde kullanılmıştır.

\section{BULGULAR}

Çalışmamıza katılan 216 çocuk hekiminin 175'i $(\% 80,7)$ kadın, 41'i $(\% 19,3)$ erkekti. Katılımcıların çoğunluğu (\%59,3) 25-35 yaş aralığında iken, 50'si $(\% 23,1)$ bir yıldan az, 74'ü $(\% 34,3)$ on bir yıldan fazla süredir çocuk hekimliği yapmaktaydı. Katılımcılar arasında unvanlara bakıldığında \%1,4 ile en az profesör, \%52,3 oranla en fazla asistan hekimler mevcuttu. (Tablo 1). En uzun süre yaşanılan yer sorusunu 214 kişi $(\% 99,1)$ il merkezi olarak yanıtladı.

Tablo 1. Katılımcıların Demografik Bilgileri

\begin{tabular}{|c|c|c|c|}
\hline Değişken & & $\mathbf{n}$ & $\%$ \\
\hline \multicolumn{4}{|l|}{ Cinsiyet } \\
\hline & Erkek & 41 & 19,3 \\
\hline & Kadın & 175 & 80,7 \\
\hline \multicolumn{4}{|l|}{ Yaş } \\
\hline & $\leq 25$ & 6 & 2,8 \\
\hline & $25-35$ & 128 & 59,3 \\
\hline & $35-45$ & 46 & 21,3 \\
\hline & $\geq 45$ & 36 & 16,7 \\
\hline \multicolumn{4}{|l|}{ Unvan } \\
\hline & Asistan & 113 & 52,3 \\
\hline & Uzman & 66 & 30,6 \\
\hline & Doçent & 34 & 15,7 \\
\hline & Profesör & 3 & 1,4 \\
\hline \multicolumn{4}{|c|}{ Meslekteki Görev Süresi } \\
\hline & $\leq 1 \mathrm{Yll}$ & 50 & 23,1 \\
\hline & 1-5 Yıl & 67 & 31 \\
\hline & 6-10 Yוl & 25 & 11,6 \\
\hline & $\geq 11$ Yıl & 74 & 34,3 \\
\hline \multicolumn{4}{|c|}{ Medeni Hali } \\
\hline & Bekar & 83 & 38,5 \\
\hline & Evli & 133 & 61,5 \\
\hline
\end{tabular}

GTT uygulamaları konusunda bilgi düzeylerine bakıldığında en fazla bilgi sahibi olunan konular sırasiyla probiyotikler \%29,2 (n:63), masaj \%13,4 (n:29), 
balneoloji \%11,5 (25) ve akupunktur \%8,7 (n:19) ve bitkisel tedaviler \%8,7 (n:19) olarak saptand1. Ayurveda, Kayropraktik, TaiChi/QiGong ve Osteopati hakkında ise hiçbir katılımcının bilgisi yoktu (Tablo 2). GTT uygulamaları konusunda en çok bilgi alınan kaynaklar sorusunda, 88 kişi $(\% 40,7)$ internet ve sos- yal medyadan, 30'ar kişi $(\% 13,9)$ televizyon programları ve kitap/gazetelerden, 29 kişi $(\% 13,4)$ doktor arkadaşlarından ve 21 kişi $(\% 9,7)$ akraba ve komşularından öğrendiklerini söylemişlerdir. Hekimlerin sadece $\% 4,2$ 'si tıp fakültesi eğitim sürecindeki derslerden bilgi sahibi olduklarını belirtmişlerdir (Tablo $3)$.

Tablo 2: GTT Yöntemleri ile İlgili Bilgi Düzeyi

\begin{tabular}{|c|c|c|c|c|c|c|c|c|}
\hline \multirow[t]{2}{*}{ GTT YÖNTEMLERİ } & \multicolumn{6}{|c|}{ BİLGİ DÜZEYİ } & Bilgim & Yok \\
\hline & $\mathbf{n}$ & $\%$ & $\mathbf{n}$ & $\%$ & $\mathbf{n}$ & $\%$ & $\mathbf{n}$ & $\%$ \\
\hline Bitkisel tedaviler & 19 & 8,8 & 62 & 28,7 & 82 & 38 & 53 & 24,5 \\
\hline Aromaterapi & 5 & 2,3 & 20 & 9,3 & 52 & 24,1 & 139 & 64,3 \\
\hline Akupunktur & 19 & 8,7 & 38 & 17,6 & 75 & 34,7 & 84 & 39 \\
\hline Kupa tedavisi & 16 & 7,4 & 25 & 11,6 & 70 & 32,4 & 105 & 48,6 \\
\hline Biyofeedbeck & 10 & 4,6 & 11 & 5,1 & 56 & 25,9 & 139 & 64,4 \\
\hline Probiyotikler & 63 & 29,2 & 92 & 42,6 & 46 & 21,3 & 15 & 6,9 \\
\hline Hipnoz & 5 & 2,4 & 13 & 6 & 80 & 37 & 118 & 54,6 \\
\hline Meditasyon/yoga & 11 & 5 & 33 & 15,3 & 85 & 39,4 & 87 & 40,3 \\
\hline Reiki & 7 & 3,2 & 12 & 5,6 & 23 & 10,6 & 174 & 80,6 \\
\hline Hirudoterapi (sülük tedavisi) & 8 & 3,7 & 14 & 6,5 & 72 & 33,3 & 122 & 56,5 \\
\hline Biyoenerji & 3 & 1,4 & 15 & 6,9 & 52 & 24,1 & 146 & 67,6 \\
\hline Ozon tedavisi & 14 & 6,5 & 18 & 8,3 & 70 & 32,4 & 114 & 52,8 \\
\hline Hidroterapi & 6 & 2,8 & 12 & 5,6 & 61 & 28,2 & 137 & 63,4 \\
\hline Homeopati & 2 & 0,9 & 4 & 1,9 & 45 & 20,8 & 165 & 76,4 \\
\hline Tai Chi/ Qi Gong & 0 & 0 & 4 & 1,9 & 35 & 16,2 & 177 & 81,9 \\
\hline Masaj & 29 & 13,4 & 44 & 20,4 & 67 & 31 & 76 & 35,2 \\
\hline Terapötik dokunma & 5 & 2,3 & 12 & 5,6 & 53 & 24,5 & 146 & 67,6 \\
\hline Refleksoloji & 8 & 3,7 & 14 & 6,5 & 41 & 19 & 153 & 70,8 \\
\hline Ayurveda & 0 & 0 & 5 & 2,3 & 35 & 16,2 & 176 & 81,5 \\
\hline Osteopati & 0 & 0 & 10 & 4,6 & 38 & 17,6 & 168 & 77,8 \\
\hline Müzik tedavisi & 18 & 8,3 & 29 & 13,4 & 60 & 27,8 & 109 & 50,5 \\
\hline Balneoloji (kaplıca) & 25 & 11,5 & 40 & 18,5 & 58 & 26,9 & 93 & 43,1 \\
\hline Kiropraktik & 2 & 0,9 & 8 & 3,7 & 25 & 11,6 & 181 & 83,8 \\
\hline Apiterapi & 3 & 1,4 & 2 & 0,9 & 41 & 19 & 170 & 78,7 \\
\hline Kayropraktik & 0 & 0 & 7 & 3,2 & 23 & 10,7 & 186 & 86,1 \\
\hline
\end{tabular}


Tablo 3. Katılımcıların GTT Konusunda Bilgi Aldıkları Kaynaklar

\begin{tabular}{|c|c|c|}
\hline Bilgi Kaynakları & $\mathbf{n}$ & $\%$ \\
\hline Doktor Arkadaşlarımdan & 29 & 13,4 \\
\hline Tıp Fakültesindeki Derslerden & 9 & 4,2 \\
\hline Akraba ve Komşularımdan & 21 & 9,7 \\
\hline Tv Programlarından & 30 & 13,9 \\
\hline İnternet ve Sosyal Medyadan & 88 & 40,7 \\
\hline Kitap ve gazetelerden & 30 & 13,9 \\
\hline Diğer (Kurs, Seminer vb.) & 9 & 4,2 \\
\hline
\end{tabular}

Hekimlerden 196 kişi $(\% 90,7)$ daha önce GTT eğitimi almadığını, 20 kişi $(\% 9,3)$ ise bu konuda eğitim aldığını belirtmiştir. Eğitim alanların \%4'ü tıp fakültesi eğitimi sürecindeki derslerden, \%6'sı uzmanlık, \%5'i asistanlık, \%5'i ise pratisyen hekimlik döneminde katıldığı seminer ve toplantılardan GTT uygulamaları ile ilgili bilgiler edindiğini belirtmiştir.

GTT yöntemlerine karşı tutumlar konusunda hekimlerin görüşleri değerlendirildi (Tablo 4). Tablo 4'te 'doğru' seçeneği katılımcının yazılan görüşü doğru bulduğu, 'yanlış' seçeneği görüşü doğru bulmadığ1 ve 'kararsızım' seçeneği ise hekimin karar veremediği yönünde değerlendirildi. Bu değerlendirmelere göre 172 kişi $(\% 79,6)$ GTT yöntemlerinin hekime danışılmadan kullanılmasının yanlış olduğunu ve bu yöntemlerin sadece doktor tavsiyesiyle kullanılması gerektiğini belirtmiştir. 138 kişi $(\% 63,9)$ GTT yöntemlerinin tıbbi tedavi kadar etkili olmadığını düşünmektedir. 132 kişi (\%61) GTT yöntemlerinin tıbbi tedavinin yetersiz veya etkisiz olduğu hastalıklarda kullanılmasını doğru bulmaktadır. Tıbben tedavisi mümkün olmayan hastalıklarda GTT yöntemlerinin kullanılmasının 85 kişi $(\% 39,4)$ doğru olduğunu, 36 kişi $(\% 16,7)$ yanlış olduğunu belirtirken, 95 kişi (\%44) ise bu konuda kararsız kalmıştır. Yüz otuz yedi kişi $(\% 63,4)$ hekimlerin hastalarını GTT yöntemlerini konusunda uyarmasının gerekli olduğunu düşünmektedir. Yüz seksen üç kişi $(\% 84,7)$ en yaygın kullanılan GTT yöntemlerinin kullanımı, etkinliği, güvenirliliği konusunda çocuk hekimlerinin bilgi sahibi olması gerektiğini düşünmektedir.

Sağlıklı çocuklara hastalıklardan korumak amacıyla GTT yöntemleri uygulanmasını 62 kişi $(\% 28,7)$ doğru, 98 kişi $(\% 45,4)$ yanlış bulurken, 56 kişi $(\% 25,9)$ bu konuda kararsız kalmıştır. Yüz yetmiş iki $(\% 79,6)$ hekime göre GTT yöntemlerinin çocuklarda kullanılması ciddi yan etkilere neden olabilmektedir. Yüz otuz yedi kişi $(\% 63,4)$ kontrollü klinik araştırmalarla yararı ispatlanmamış tıp dışı yöntemlerin hiçbir hastalıkta kesinlikle kullanılmaması gerektiğini, 118 kişi (\%54,6 ) bu yöntemlerin hastaların doğru tedaviyi almalarını geciktirdiğini düşünmektedir. Tablo 5'de 'evet' seçeneği katılımcıların GTT konularının Tıp fakültesi eğitim müfredatında yer almasını istediklerini, 'hayır' seçeneği istemediklerini, 'kararsızım' seçeneği ise bu konuda karar veremediklerini göstermektedir. GTT yöntemlerinin çeşitleri, bilimsel olarak ispatlanmış yarar ve zararları tıp fakültesi eğitim sürecinde ders olarak anlatılmalı mı sorusunu 149 kişi (\%69) evet, 29 kişi (\%13,4) hayır, 38 kişi $(\% 17,6)$ ise kararsızım şeklinde yanıtlamıştır (Tablo 5). 
Tablo 4. GTT Yöntemleri ile İlgili Çocuk Hekimlerinin Görüşleri

\begin{tabular}{|c|c|c|c|c|c|c|}
\hline & \multicolumn{2}{|c|}{ Doğru } & \multicolumn{2}{|c|}{ Yanlış } & \multicolumn{2}{|c|}{ Kararsizım } \\
\hline & $\mathbf{n}$ & $\%$ & $\mathbf{n}$ & $\%$ & $\mathbf{n}$ & $\%$ \\
\hline GTT Yöntemleri doktora danışılmadan kullanılabilir & 12 & 5,6 & 172 & 79,6 & 32 & 14,8 \\
\hline GTT Yöntemleri tıbbi tedavi kadar etkilidir & 26 & 12 & 138 & 63,9 & 52 & 24,1 \\
\hline $\begin{array}{l}\text { GTT Yöntemleri tıbbi tedavinin yetersiz veya etkisiz olduğu } \\
\text { hastalıklarda tedaviye ek olarak kullanılabilir. }\end{array}$ & 132 & 61 & 31 & 14,3 & 53 & 24,7 \\
\hline $\begin{array}{l}\text { Tibben tedavisi mümkün olmayan bir hastalığı GTT yöntemle- } \\
\text { riyle şifası mümkün değildir. }\end{array}$ & 85 & 39,4 & 36 & 16,6 & 95 & 44 \\
\hline $\begin{array}{l}\text { Hekimler hastalarını bitkisel ilaç ve gıda katkılarını kullanmak- } \\
\text { tan sakınmaları konusunda uyarmalıdır. }\end{array}$ & 137 & 63,4 & 29 & 13,5 & 50 & 23,1 \\
\hline $\begin{array}{l}\text { Hekimler, halk arasında en yaygın kullanılan GTT yöntemleri- } \\
\text { nin kullanımı, etkinliği ve güvenirliliği konusunda bilgi sahibi } \\
\text { olmalıdır. }\end{array}$ & 183 & 84,7 & 9 & 4,2 & 24 & 11,1 \\
\hline $\begin{array}{l}\text { Sağlıklı çocuklara hastalıklardan korumak amacıyla GTT yön- } \\
\text { temleri uygulanabilir }\end{array}$ & 62 & 28,7 & 98 & 45,4 & 56 & 25,9 \\
\hline $\begin{array}{l}\text { GTT yöntemlerinin kullanılması özellikle çocuk hastalarda } \\
\text { ciddi istenmeyen etkilere neden olabilir. }\end{array}$ & 172 & 79,6 & 15 & 7 & 29 & 13,4 \\
\hline $\begin{array}{l}\text { Kontrollü klinik araştırmalarla yararı ispatlanmamış tıp dışı } \\
\text { yöntemler hiçbir hastalıkta kesinlikle kullanılmamalıdır. }\end{array}$ & 137 & 63,4 & 42 & 19,4 & 37 & 17,2 \\
\hline $\begin{array}{l}\text { GTT yöntemleri, insanların doğru tıbbi tedaviyi almalarını ge- } \\
\text { ciktirir. }\end{array}$ & 118 & 54,6 & 28 & 13 & 70 & 32,4 \\
\hline
\end{tabular}

Tablo 5. Katılımciların Tip Fakültesi Müfredatında GTT Konularının Yer Alması Konusundaki Görüşleri

\begin{tabular}{lcc}
\hline & $\mathbf{n}$ & \% \\
\hline Evet & 149 & 69 \\
Hayır & 29 & 13,4 \\
Kararsızım & 38 & 17,6 \\
\hline \hline
\end{tabular}

Katılımcılardan 120 kişinin (\%55,6) daha önce kendisine GTT yöntemlerinden en az birini uyguladığ $\breve{1}$, 102 kişinin $(\% 47,2)$ ise hastalarına önerdiği saptanmıştır. En çok kullanılan yöntemlerin masaj (\%21,8), bitkisel tedaviler $(\% 9,7)$ ve akupunktur $(\% 8,8)$ olduğu görülmüştür. Kullanma nedenleri sorusunu 41 kişi (\%19) sağlık problemleri için, 27 kişi $(\% 12,5)$ yorgunluğu gidermek için, 16 kişi $(\% 7,4)$ stres atmak için ve 13 kişi (\%6) kilo vermek için olarak yanıtlamıştır. Hastalara en çok önerilen GTT yöntem- leri ve önerilme nedenleri incelendiğinde, katılımcıların \%50'si infantil kolik için bitki çayları ve probiyotikleri, \%43'üü üst solunum yolu semptomlarını rahatlatmak için bitki çayları ve gıda takviyelerini, \%35'i bağışıklık sistemini güçlendirmek için bal, vitamin ve gida takviyelerini, $\% 29^{\prime}$ u ise anemi için gıda takviyelerini önerdiği saptanmıştır. GTT uygulamalarını kullanan hasta sayısı sorusuna; 72 kişi $(\% 33,3) 0$ hasta, 16 kişi ise $(\% 7,4) 101$ den fazla sayıda hasta olarak cevap vermiştir (Tablo 6). 
Tablo 6. Hekimlerin GTT Uygulamaları Kullanan Hasta Sayısı

\begin{tabular}{ccc}
\hline \hline Hasta Sayısı & Hekim Sayıs & $\%$ \\
\hline 2 & 58 & 26,9 \\
$3-10$ & 65 & 30,1 \\
$11-50$ & 37 & 17,1 \\
$51-100$ & 30 & 13,9 \\
$>101$ & 26 & 12 \\
\hline \hline
\end{tabular}

\section{TARTIŞMA}

Modern tıp tarafından kabul edilmeyen veya tıbbi tedaviye ek olarak uygulanan tedavi yaklaşımları GTT uygulamaları olarak tanımlanmaktadır (Altern Ther Health Med., 1997). Son yıllarda GTT uygulamalar1nın kullanımı, tüm dünyada erişkinlere paralel olarak çocuklarda da artış göstermiştir (Bülbül ve ark., 2009). Çocukların tedavisinde ilaç kullanmak istemeyen aileler, GTT uygulamalarına yönelmeye başlamışlardır. Ailelerin bu uygulamaları kullanmadan önce, bu uygulamaların kanita dayalı olup olmad1ğını öğrenme konusunda bilinçlendirilmesi gerekmektedir (Özcebe, 2008). Bu bilinçlendirmeyi yapacak kişilerin de herhangi bir sağlık sorununda çocuğu gören, takip ve tedavi eden başta çocuk hekimlerinin olması beklenir. Bu nedenle çocuk hekimlerinin GTT uygulamalarının kullanımına ilişkin bilgi düzeyinin araştırılıp, tutum ve davranışlarının ortaya konulması ve bu uygulamalar konusunda gereken eğitimlerin planlanması önem arz etmektedir.

Çalışmamızda çocuk hekimleri arasında en iyi bilinen GTT yöntemlerinin sirasıyla probiyotikler, masaj, balneoloji, akupunktur ve bitkisel tedaviler olduğu saptanmıştır. Altan ve ark. tarafından yapılan bir çalışmada tıp fakültesi öğrencileri kendilerini masaj, meditasyon/yoga ve bitkisel tedaviler konularında daha bilgili gördüklerini belirtmişlerdir (Altan ve ark., 2014). Ülkemizde yapılan bir başka çalışmada hekimlerin en çok bildikleri GTT yöntemlerinin bitkisel tedaviler, akupunktur ve hipnoz olduğu tespit edilmiştir (Akan ve ark., 2012). İngiltere'de yapilan bir araştırmada ise hekimlerin GTT yöntemleri ile ilgili bilgi düzeylerinin ortalama \%25-30 olduğu ve en sık bilinen konuların homeopati, akupunktur ve masaj olduğu bildirilmiştir (Furnham ve ark., 2003). Günümüzde sayıları giderek artan bilimsel araştırma sonuçları, probiyotiklerin, birçok hastalığın tedavisinde hatta önlenmesinde kullanılabileceğine işaret etmektedir (Hao ve ark., 2015; Grev, 2018; Scott ve ark., 2019). Bu nedenle seminer ve eğitim toplantılarında probiyotiklerin daha fazla yer alması, çocuk hekimlerinin bu konuda daha fazla bilgi sahibi olmasını açıklamaktadır. Çalışmamızda en iyi bilinen GTT yönteminin probiyotikler oluşunun, bunun bir sonucu olduğu düşünüldü. Masaj ve Akupunktur, ülkemizde ve pek çok ülkede en bilinen yöntemler arasındadır. Yine bitkisel tedaviler, ülkelerin kültürel ve coğrafi konumuna göre değişmekle birlikte her dönemde iyi bilinen GTT yöntemleri arasında ilk s1ralarda yer almaktadır (Yüksel ve ark., 2019). Ülkemizde kaplica turizminin giderek gelişmesi ve balneoterapi hizmeti veren tesis sayısının artması, hekimlerin bu konuya ilgisinin artmasına neden olmuş olabilir. Akupunktur dışında farklı ülkelerde hekimlerin duyduğu ve bildiği yöntemlerin farklılık göstermesi, değişik kültürler ve yasal düzenlemelerle açık- 
lanabilir. ABD'de osteopati eğitimi veren fakültelerin bulunması nedeniyle, özellikle Kuzey Amerika kitasında osteopati ve benzer uygulamalar yapan kayropraktik daha çok bilinmektedir (Yüksel ve ark., 2019). Ülkemizde 2014 yılında yapılan bir çalışmada, en az bilinen yöntemlerin kayropraktik(\%4), apiterapi $(\% 4,5)$, osteopati $(\% 7)$ ve homeopati (\%7) olduğu saptanmıştır (Lafçı ve Kaşıkçı, 2014). Kayropraktik, apiterapi, osteopati ve homeopati yöntemlerinin hekimler arasında çok düşük düzeyde biliniyor olmasının sebebi, bu yöntemlerin ne okulda ne de medyada yeterince işlenmemesinden kaynaklandığı düşünülmektedir.

Çalışmamızda çocuk hekimleri, GTT yöntemleri hakkındaki bilgiye çoğunlukla internet ve sosyal medya $(\% 40,7)$, televizyon programları $(\% 13,9)$ ve kitap/gazetelerden $(\% 13,9)$ ulaştıklarını belirtmişlerdir. Katılımcıların sadece \%4,2'sinin bilgi kaynağının, tıp fakültesi eğitim sürecindeki dersler olması da çalışmamızın dikkat çekici bir sonucudur. Çalışmamizda bu sonuca paralel olarak hekimlerin büyük çoğunluğu, GTT yöntemleri hakkında tıp fakültesinde yeterli eğitim verilmediğini düşünmektedir. Ayrıca katılımcıların \%69'unun tıp fakültesi eğitim sürecinde, GTT yöntemlerinin olası yarar ve zararları konusunda eğitim almak istediği de saptanmıştır. Ülkemizde yapılan iki ayrı çalışmada internet ve televizyon programları GTT yöntemleri hakkında bilgi kaynakları konusunda ilk sirada yer almaktadır (Altan ve ark., 2014; K1lıç ve ark., 2009). Amerika' da yapılan bir araştırmada GTT yöntemlerinin öğrenildiği bilgi kaynağı olarak internet ilk sırada yer almakta; onu dergi, gazete ve kitaplar izlemektedir (Lie ve ark., 2006). İtalya ve Katar' da pratisyen hekimler arasında yapılan iki ayrı çalışmada, hekimlerin çoğunluğunun GTT yöntemleri hakkında eğitim almadıkları ve eğitim almayı istedikleri belirtilmiştir (Giannelli ve ark., 2007; Iamsa ve ark., 2010). Ülkemizde 2020 ve 2019 yıllarında yapılan iki yeni çalışmada da benzer sonuçlar bildirilmiştir (Yüksel ve ark., 2019; Basatemür ve ark., 2020). Çalışmaların da gösterdiği gibi GTT yöntemlerinin toplum içinde, sağlık profesyonelleri arasında dahi, yayılımı ve bilinmesinde medyanın önemi büyüktür. Bu noktada televizyon programları, internet ve sosyal medya aracılığıyla topluma verilen GTT yöntemleri hakkındaki bilgilerin, gerekli mecralarca sıkı denetlenmesi uygun olacaktır. Ayrıca çalışmamızda, literatürdeki diğer çalışmalara benzer şekilde hekimlerin, tıp fakültesi sürecinde GTT yöntemleri hakkında herhangi eğitim almadıkları ve yine büyük çoğunluğun, bu yöntemlerin ders olarak anlatılmasını istedikleri saptanmıştır. Ülkemizde tıp fakültesi ve uzmanlık eğitiminde GTT yöntemleri ile ilgili büyük eksiklikler mevcuttur. Tıp fakültesi eğitim müfredatında GTT yöntemlerine yer verilip verilmemesi, konunun uzmanları tarafından tartışılmalıdır ancak bunun için GTT yöntemleri konusunda daha fazla bilgi sahibi olmak ve bilimsel verilerin daha geçerli olmasını beklemek gerekebilir.

Yaptığımız çalışmada, çocuk hekimlerinin \%55,6'sınin daha önce kendisine GTT yöntemlerinden en az birini uyguladığı, \%47,2'sinin ise hastalarına önerdiği saptanmıştır. Katılımcıların kullandığı GTT yöntemleri arasında ilk üç sırayı masaj, akupunktur ve bitkisel tedaviler almıştır. Hastalara önerilen en sık yöntemin ise probiyotikler ve bitkisel tedaviler olduğu tespit edilmiştir. Altan ve ark. tarafından yapılan bir araştırmada, hekim adaylarının GTT yöntemleri arasında en çok masaj ve bitkisel tedavileri kullanarak deneyimledikleri ve hastalara da en çok bu iki yöntemi önerdikleri belirtilmiştir. Yapılan farklı çalışmalarda da masaj en fazla deneyimlenen ve kullanılan yöntem olarak tespit edilmiştir (Lie ve ark., 2006; Chaterji ve ark., 2007). Amerika' da yap1lan bir araştırmaya göre diyet, bitkisel tedaviler ve kiropraktik en çok kullanılan yöntemler arasında yer almıştır (Lamarine ve ark., 2003). GTT yöntemlerinden masajın, hemen daima en çok deneyimlenen yöntem olması, bilimsel olarak kanıtlanmış yararları ve modern tıp tarafından da kullanılan bir yöntem olmasıyla açıklana-bilir. Masaj, vücuda yapılan mekanik uyarılara cevap şeklinde gerçekleşen bir dizi reaksiyon meydana getirir. Bu reaksiyonlarla; hücrelerin rejenerasyonunu sağlama, hücrelerin beslenmesini arttırma, solunum yollarındaki sekresyonları mobilize etme, barsak peristaltizmini arttırarak 
konstipasyon kolik gibi yakınmaları azaltma, venöz kan ve lenf akımı arttırarak toksik maddelerin vücuttan uzaklaşmasını sağlama, kasların beslenmesi, kas ağrısı ve hasa-rının önlenmesi, gevşemeyi sağlama, endokrin sistem ve otonom sinir sistemi üzerinde refleks etkiler oluşturma, endorfinlerin salınımını kolaylaştırarak ağrının inhibisyonuna yardım etme gibi multisistemik pek çok yararlı etki oluşturabilir (Kara, 2019). Bitkisel tedavi yönteminin yine en s1k kullanılan yöntemler arasında olması, ülkeler arasında bitki çeşitliliği değişmekle beraber, halk arasında geleneksel kullanım yaygınlığı ile açıklanabilir. Çalışmamızda hastalara önerilen yöntemlerden probiyotiklerin öne çıkmasının nedeni, katılımcılarımızın çocuk hekimleri olması ve çocuk hastalarda probiyotik kullanımının giderek artmasıyla açıklanabilir. Ayrica son zamanlarda probiyotiklerin önemini vurgulayan bilimsel çalışma sayısının hızla artışı, hekimleri bu yöntem hakkında daha da bilgilendirmiş ve probiyotikleri hastalarına tereddütsüz önerebilecekleri bir yöntem haline getirmiş olabilir.

Araştırmamızda çocuk hekimlerinin, GTT yöntemlerine temkinli ve şüpheci yaklaşımları dikkat çekmiştir. Bu durumun, bu yöntemlerin çeşitliliği ve henüz bilinmeyen pek çok etkilerinin oluşundan kaynaklandığı düşünülmektedir. Hekimlerin çoğunluğu, GTT yöntemlerinin kendilerine danışılmadan kullanılmasının yanlış olduğunu belirtmiştir. GTT yöntemlerinin çocuklarda kullanılmasının ciddi yan etkilere neden olabileceği ve klinik araştırmalarla yararı ispatlanmamış tıp dışı yöntemlerin hiçbir hastalıkta kesinlikle kullanılmaması gerektiği, katılımcıların çoğu tarafından onay almıştır. Ayrıca hekimler, bu yöntemlerin çocuk hastaların doğru tedaviyi almalarını geciktirdiğini de düşünmektedir. Tuncel ve ark. tarafından ülkemizde yapılan bir çalışmada, çocuklarda GTT kullanımının oldukça sık olduğu, pediatristlerin tıp dışı yöntemlerin etkileri ve yan etkileri konusunda aileleri bilgilendirmesi gerektiği vurgulanmıştır. Aynı çalışmada ailelerin, çocuklarının basit ve kolaylıkla tıbbi yöntemlerle tedavi edilebilecek hastalıklarında dahi hemen GTT yöntemlerine başvurduğu ve olası olumsuz etkileri ile ilgili herhangi bir bilgi sahibi olmadıkları da belirtilmiştir(Tuncel ve ark., 2014).

Çocuklar, ilaç ve maddelerin emilimi, metabolizması ve atılımı konusunda yetişkinlerden farklıdır. Karaciğer ve böbrek fonksiyonları fizyolojik olarak immatür olduğu için ilaç ya da maddelerden daha fazla etkilenirler. Bu nedenle çocuklarda yan etkiler daha şiddetli ve ölümcül olabilir (Woolf, 2003). Tip dişı yöntemlerin çocuklarda oluşturduğu olumsuz etkilerden bahseden pek çok çalışma mevcuttur (Bateman ve ark., 1998; Ernst, 2003). Bazı bitkisel tedavilerin alerjik reaksiyonlara, başta karaciğer, böbrek ve kalp olmak üzere organlarda fonksiyon bozukluklarına ve kanserojen etkilere neden olabildiği gösterilmiştir. Ayrıca GTT yöntemlerinden Akupunkturun ardından pnömotoraksa, kalp tamponadına veya omurilik yaralanmasına yol açan mekanik yaralanmalar görülebilir. Akupunktur sonrası bulaşıcı komplikasyonlar olarak HIV (Human Immunodeficiency Virus), hepatit ve bakteriyel endokardit saptanabilir (Niggemann ve Grüber, 2003; Ernst, 2003). Çalışmamızda katılımcıların çoğu, hekimlerin hastalarını GTT yöntemlerini konusunda uyarmasının gerekli olduğunu ve en yaygın kullanılan GTT yöntemlerinin kullanımı, etkinliği, güvenirliliği konusunda çocuk hekimlerinin bilgi sahibi olması gerektiğini düşünmektedir. Tibben tedavisi mümkün olmayan hastalıklarda GTT yöntemlerinin kullanılmasının hekimlerin \%39,4'ü doğru olduğunu düşünürken, \%44 oranla çoğunluk kararsız kalmıştır. Kararsız kalan oranın azımsanamayacak boyutta oluşu, hekimlerin GTT yöntemleri konusunda yeterli düzeyde bilgi sahibi olmadıklarını düşündürmektedir. GTT yöntemlerinin özellikleri, bilimsel olarak ispatlanmış yarar ve zararlarının tıp fakültesi veya uzmanlık eğitim sürecinde ders olarak anlatılmasını, çoğu çocuk hekimi gerekli bulmaktadır. Bu sonuçlarda da görüldüğü gibi çocuk hekimleri, hastalarına daha iyi hizmet verebilmeyi ve doğru yönlendirebilmeyi istemekte ancak bu konuda yeterli eğitime sahip olmadığını düşünmektedir. 
Sonuç olarak; GTT yöntemleri, ülkemiz ve dünyanın diğer ülkelerinde önemli oranda varlığını sürdürmekte, sağlıklı ve hasta çocuklarda bu yöntemlerin bilinçsizce kullanımı her geçen gün daha da artmaktadır. En masum görünen yöntemlerin bile istenmeyen ciddi yan etkileri olabileceği unutulmamalı ve bu yöntemler konusunda aileler ayrıntılı bilgilendirilmelidir. Bu konuda en büyük görev çocuk hekimlerine düşmektedir. Çalışmamızda, çocuk hekimlerinin GTT yöntemleri ile ilgili bilgi düzeylerinin yeterli olmadığı ve bu bilgileri çoğunlukla eğitim sürecinde öğrenmedikleri ancak tıp eğitiminde yer verilmesini ve modern tıp ile entegre olarak kullanılmasını istedikleri saptanmıştır. Çocuk hekimlerinin, ülkemizde en sık kullanılan GTT yöntemlerinin, özellikleri, güvenirliliği ve olası istenmeyen etkileri konusunda bilimsel bilgi ile donatılmalarının uygun olacağı söylenebilir. Tıp fakültesi veya uzmanlık eğitimi sürecinde müfredatta düzenlemeler yapılması ve çocuk hekimlerini de kapsayan GTT eğitimlerinin planlanması, bu konudaki boşluğu dolduracaktır.

\section{Çıkar Çatışması}

Yazarlar çıkar çatışması olmadığını beyan eder.

Finansal Destek: Yazarlar bu çalışma için finansal destek almadıklarını belirtmişlerdir.

\section{KAYNAKLAR}

Akan H, İzbirak G, Kaspar E, Apaydın Kaya Ç, Aydin S, Demircan N et al., Knowledge and attitudes towards complementary and alternative medicine among medical students in Turkey. BMC Complement Alternat Med 2012;12:115.

Altan S, Rahman S, Çam S. Tıp fakültesi öğrencilerinin tamamlayıcı ve alternatif tıp yöntemleri ile ilgili bilgi ve tutumları. Turk Klin J Med Ethics 2014;22(3):81-8.

Ayhan H, Mollahaliloğlu S. Tibbi sülük tedavisi: hirudoterapi. Ankara Med J 2018;18(1):141-8.

Basatemür M, Güneş G, Aylaz R. Tıp fakültesi öğrencilerinin geleneksel ve tamamlayıc tedavi konusunda bilgi, tutum ve davranışları. ESTÜDAM Halk Sağ Derg 2020;5(1):43-52.
Bateman J, Chapman RD, Simpson D. Possible toxicity of herbal remedies. Scot Med J 1998;43:715.

Benli Z. Hacamat tedavisi. Uluslararası Sos Bil Derg 2017;1(6):46-53.

Bülbül SH, Turgut M, Köylüoğlu S. Çocuklarda tıp dışı alternatif uygulamalar konusunda ailelerin görüşleri. Çocuk Sağ Hastalık Derg 2009;52:195202.

Chaterji R, Tractenberg RE, Amri H, Lumpkin M, Amorosi S, Hamarati A et al. A large sample survey of first and second year medical student attitudes toward complementary and alternative medicine in the curriculum and in practice. Alter Ther Health Med. 2007;13(1):30-5.

Coşkun T. Pro-, pre- ve sinbiyotikler. Çocuk Sağ Hastalık Derg 2006;49:128-48.

Defining and describing complementary and alternative medicine. Panel on Definition and Description, CAM Research Methodology Conference, April 1995. Altern Ther Health Med 1997;3:49-57.

Ergin A, Hatipoğlu C, Bozkurt Aİ, Mirza E, Kunak D, Karan C et al. Uzmanlık ve tıp öğrencilerinin tamamlayıcı-alternatif tıp hakkındaki bilgi düzeyleri ve tutumları. Pamukkale Tip Derg 2011;4(3):136-43.

Ernst E. Prevalence of use of complementary/ alternative medicine: a systematic review. Bull World Health Organ 2000; 78: 252-7.

Ernst E. Serious adverse effects of unconventional therapies for children and adolescents: a systematic review of recent evidence. Eur J Pediatr 2003;162:72-80.

Furnham A, McGill C. Medical students' attitudes about complementary and alternative medicine. J Altern Complement Med 2003;9(2):275-84.

Giannelli M, Cuttini M, Fre MD, Buiatti E. General practitioners' knowledge and practice of complementary / alternative medicine and its relation ship with life-styles: a population-based survey in Italy. BMC Fam Pract 2007;8: 30. 
Grev J, Berg M, Soll R. Maternal probiotic supplementation for prevention of morbidity and mortality in preterm infants. Cochrane Database Syst Rev 2018;12: CD012519.

Hao Q, Dong BR, Wu T. Probiotics for preventing acute upper respiratory tract infections. Cochrane Database Syst Rev 2015; 2:CD006895.

Herring MA, Roberts MM. Complementary and Alternative Medicine: Fast Facts For Medical Practice. Inc. A Blackwell Publishing Company, 2002; United States of America

IAMSA S, Ismail MFS, YousufWAAA, Salama RE. Knowledge, attitudes and practice of general practitioners towards complementary and alternative medicine in Doha, Qatar. East Mediterr Health J 2010;16(5):522-7.

Kara E, Ünver G. (2019). Masaj ve toparlanmaya etkileri. Gaziantep Üniv Spor Bil Derg 2019;4(1):28-49.

Kemper KJ, Vohra S, Walls R. The task force on complementary and alternative medicine and the provisional section on complementary, holistic, and integrative medicine. the use of complementary and alternative medicine in pediatrics. Pediatrics 2008;122:1374-86.

Kılıç S, Ogur R, Yaren H, Akkoyun NG. Knowledge of and attitudes toward complementary and alternative medicine amongst medical students in a Turkish medical school. Pak J Med Sci 2009;25(2):319-24.

Kutlubay Z, Engin B, Serdaroğlu S, Tüzün Y. Dermatoloji'de Ozon Tedavisi. Dermatoz Derg 2010;4(1):208-16.

Lafçı D, Kaşıkçı MK. Yataklı sağlık kuruluşunda görev yapan sağlık personelinin tamamlayıcı ve alternatif tedavi yöntemlerini bilme ve kullanma durumları. Gümüşhane Üniv Să̆ Bil Derg 2014;3(4):1114-31.

Lamarine L, Fisher KJ, Sbarbaro V. Alternative medicine attitudes and practices of US. College students: an exploratory study. Calif J Health Promot 2003;1(4):24-9.
Lie DA, Boker J. Comperative survey of complementary and alternative medicine attitudes, use and information-seeking behaviour among medical students, residents and faculty. BMC Med Educ 2006;9(6):58.

Niggemann B, Grüber C. Side-effects of complementary and alternative medicine. Allergy 2003;58:707-16

Orhan F, Sekerel BE, Kocabaş CN, Saçkesen C, Adalıoğlu G, Tuncer A ve ark. Complementary and alternative medicine in children with asthma. Ann Allergy Asthma Immunol 2003; 90: 611-5.

Özcebe H. Çocuklarda Alternatif Tip Uygulamalarında Kanıta Dayalı Yaklaşım. Koruyucu Çocuk Sağlığında Beslenme ve Alternatif Tip Uygulamaları Sempozyumu Kitapçığı, 6-8 Kasım 2008, Kirikkale.

Pearson NJ, Chesney M. The national center for complementary and alternative medicine. Acad Med 2007;82(10):967.

Resmi Gazete (2014a) Geleneksel ve Tamamlayıc1 Tıp Uygulamaları Yönetmeliği. Tarih: 27.10.2014; Sayı: 29158

Sanders H, Davis MF, Duncan B, Meaney FJ, Haynes J, Barton LL et al. Use of complementary and alternative medical therapies among children with special health care needs in Southern Arizona. Pediatrics 2003; 111: 584-7.

Scott AM, Clark J, Julien B, Islam F, Roos K, Grimwood K, et al. Probiotics for preventing acute otitis media in children. Cochrane Database Syst Rev 2019;6:CD012941.

Tokaç M. Geleneksel tıbba akademik yaklaşım GETTAM. SD Sağlık Düşüncesi Tip Kült Derg 2013;28:82-5.

Tuncel T, Şen V, Kelekç S, Karabel M, Şahin C, Uluca Ü ve ark. Kronik hastalığı olmayan çocuklarda tamamlayıcı ve alternatif tıp kullanımı. Türk Pediatr Arş 2014; 49: 148-53.

Yildirim Y, Parlar S, Eyigor S, Sertoz OO, Eyigor C, Fadiloğlu Ç et al. An analysis of nursing and medical students' attitudes towards and 
knowledge of complementary and alternative medicine (CAM). J Clin Nurs 2010;19:1157-66.

Yüksel NA, Açıkgöz B, Yüksel C, Ayoğlu FN, Er T. Hekimlerin geleneksel ve tamamlayıcı tıp uygulamalarına bakış açısı. ESTÜDAM Halk Sağ Derg 2019;4(3):276-86.
World Health Organization. General Guidelines for Methodologies on Research and Evaluation of Traditional Medicine. Geneva: WHO Books; 2000:80.

Woolf AD. Herbal remedies and children: Do they work? Are they harmful? Pediatrics 2003;112:240-6. 